\title{
Probable Association of Hearing Loss, Hypertension and Diabetes Mellitus in the Elderly
}

\author{
Caroline Luiz Meneses-Barriviera ${ }^{1}$ Jéssica Aparecida Bazoni ${ }^{1}$ Marcelo Yugi Doi ${ }^{1}$ \\ Luciana Lozza de Moraes Marchiori ${ }^{1}$ \\ ${ }^{1}$ Center of Biological and Health Sciences, Universidade Pitágoras \\ Unopar, Londrina, Paraná, Brazil \\ Int Arch Otorhinolaryngol 2018;22:337-341.

\begin{abstract}
Address for correspondence Jéssica Aparecida Bazoni, PhD student, Centro de Ciências Biológicas e da Saúde (CCBS), Universidade Pitágoras Unopar, Rua Marselha, 183, Parque Residencial João Piza, Londrina, Paraná 86041-140, Brazil (e-mail: je_bazoni@hotmail.com).
\end{abstract}

\begin{abstract}
Introduction The aging process causes changes in body structure in a continuous manner, and contributes to clinical disorders. Life expectancy is increasing, especially in developing countries.

Objective To assess the prevalence of hearing loss and its possible association with hypertension and diabetes mellitus (DM) in the elderly.

Methods A cross-sectional study with 519 elderly individuals aged over 60 years who underwent an audiological evaluation (pure tone audiometry), and answered a comorbidity questionnaire that included questions about age, gender, tinnitus and medical history, with data concerning DM. The dependent variable was the presence of hearing loss. The independent variables were age, gender, DM and hypertension. The variables were presented in absolute numbers and proportions, and enabled us to estimate the prevalence. The statistical analysis was performed through multiple logistic regression with 95\% confidence intervals and values of $p<0.05$ for the hearing loss and its associated factors. Results A total of 519 subjects of both genders with a median age of 69 years were evaluated, and the individuals who did not attend the audiometric test were excluded from the study, so the final sample was composed of 498 subjects. Sensorineural hearing loss was more prevalent (66.26\%) of most frequently with bilateral hearing loss of $91.56 \%$ and $26.50 \%$ with mild degree. The statistical analysis showed that the

Keywords

- hearing loss

- hypertension

- diabetes variable DM was associated with the high frequency of hearing loss in the elderly, and according to the multiple logistic regression, the risk factors are independent of the hearing loss only for age and exposure to occupational noise.

Conclusions There was a statistically significant difference between hearing loss at high frequencies and the risk factors, that is, age and DM.
\end{abstract}

\section{Introduction}

According to the World Health Organization (WHO), ${ }^{1}$ the number of people over 60 years of age in Brazil will have risen from $10 \%$ to $29 \%$ of the population by $2050 .^{2}$ The WHO considers that individuals are elderly once they reach 65 years of age, but since life expectancy in Brazil is lower than that of developed countries, the Brazilian Ministry Health determines that an elderly person is an individual over 60 years old. ${ }^{2,3}$

Once longevity increases, the incidence of chronic diseases also increases, affecting the quality of life of elderly patients. ${ }^{2}$ Hearing loss (HL) is the most widespread sensory impairment found among the elderly, ${ }^{4}$ and it may lead to depression, social problems and frustration. ${ }^{5}$ received

April 4, 2017

accepted

August 24, 2017

published online

October 25, 2017
DOI https://doi.org/

10.1055/s-0037-1606644. ISSN $1809-9777$.
Copyright $(2018$ by Thieme Revinter

Publicações Ltda, Rio de Janeiro, Brazil
License terms

(요 (1) $\Theta \circledast$ 
The most common type of $\mathrm{HL}$ is presbycusis, which is due to the aging process. ${ }^{6}$ Studies have shown that HL affects $60 \%$ of the elderly population living in Brazil. ${ }^{7}$ Hearing loss, tinnitus and vertigo are associated with smoking, high blood pressure (hypertension), diabetes mellitus (DM), lifestyle, age, health history, leisure activities and exposure to occupational noise, and the incidence of auditory symptoms seems correlated with noise exposure during life. ${ }^{8-13}$

Meneses et $\mathrm{al}^{14}$ showed that people over 60 years of age mainly have sensorineural $\mathrm{HL}$, which is characterized as a progressive loss that increases with age. The risk factors, such as hypertension, diabetes, alcohol intake and smoking may predispose individuals to suffer HL, especially when associated with presbycusis.

Presbycusis is HL associated with aging, and it is the third most common chronic condition reported by the elderly. ${ }^{15}$ Clinically, in presbycusis, the typical audiometric profile observed is a bilateral symmetric high-frequency sensorineural HL that progresses with age. ${ }^{16}$ The effects of exposure to noise on hearing varies across age groups, and we emphasize the importance of applying age and gender corrections prior to determining the relative contribution to $\mathrm{HL}$ of the exposure to occupational noise. ${ }^{17}$

Individuals with DM and hypertension often have symptoms such as dizziness, tinnitus and $\mathrm{HL}$, and DM and hypertension are the conditions that are most commonly related to auditory disorders. ${ }^{18,19}$

Therefore, the present study aimed to determine the possible association of HL with hypertension and DM in the elderly.

\section{Materials and Methods}

This cross-sectional study was approved by the Ethics in Human Research Committee of our university (under number PP 0070/09). The present study is part of the first major investigation performed to assess the health of the individuals over 60 years of age being cared for in basic health units (BHUs) of the city of Londrina, in the State of Paraná, Southern Brazil. The participants were of both genders, and they were individuals who were living independently and classified at level 3 or 4 as proposed by Spirduso. ${ }^{20}$ The subjects volunteered to participate in the study, which was called 'Study on Aging and Longevity' (EELO, in the Portuguese acronym) by signing the free and informed consent form.

The sample was randomly stratified taking into account the five regions of the city of Londrina, Paraná State. From a population of 43,610 elderly individuals being cared for in 38 BHUs in the urban area of Londrina, the calculated sample was composed of 385 individuals. Taking into account probable losses in the population, the sample increased, reaching 519 individuals, of which $15 \%$ were from the Central region, $27 \%$ were from the Northern region, $23 \%$ were from the Southern region, $19 \%$ were from the Eastern region, and $16 \%$ were from the Western region. A sampling error of $5 \%$ and a power of $80 \%$ were considered for the calculation.

The routine audiological anamnesis used at the audiology clinic was applied in the present study. The anamnesis is based on the protocol for anamnesis by Miller, ${ }^{21}$ which consists of an otoscopy to examine the external acoustic meatus and the tympanic membrane and pure tone audiometry, which is considered the gold standard to evaluate the auditory threshold in adults, at frequencies between $250 \mathrm{kHz}$ and $8,000 \mathrm{kHz}$, with the presentation of the pure tones. The result was recorded in a pure tone audiometry form used in the routine care of the sector, and was subsequently inserted in the database using the WinAudio (WinAudio, Curitiba, PR, Brazil) software, so the result would be stored and could be printed for the patient.

In order to collect data about comorbidities, age, gender, HL, tinnitus and medical history on DM, we applied a selfreported questionnaire. The audiological evaluation was individually performed in a soundproof booth with a model AD-28 Interacoustics (Middelfart, Denmark) audiometer.

Regarding the criteria for $\mathrm{HL}$, we used the classification of Davis and Silverman ${ }^{22}$ to analyze the auditory average I ( $500 \mathrm{~Hz}, 1,000 \mathrm{~Hz}$, and $2,000 \mathrm{~Hz}$ ), and the classification of the National Committee on Noise ${ }^{23}$ and the study by Amorim et $\mathrm{al}^{24}$ to analyze the auditory average II $(3,000 \mathrm{~Hz}, 4,000 \mathrm{~Hz}$, and $6,000 \mathrm{~Hz}$ ). The degrees of $\mathrm{HL}$ were classified as: mild (26-40 dB), moderate (41-70 dB), severe (71-90 dB), and profound $(>91 \mathrm{~dB}) .^{22}$

The dependent variable was HL. The independent variables were age, gender, DM and hypertension. The variables were presented in absolute numbers and proportions, estimating the prevalence.

The analysis was conducted with non-parametric tests: the Chi-squared ( $\left.x^{2}\right)$ test was applied to determine the possible associations between $\mathrm{HL}$ and individuals with and without DM and hypertension, and the logistic regression was used to verify the independent risk factors for $\mathrm{HL}$.

Values of $p<0.05$, with a $95 \%$ confidence interval (CI), were considered for the univariate analyzes for inclusion in the final model of the $\mathrm{X} 2$ test and the relative risk. The tests were performed using the Bio Estat software, version 5.0.

\section{Results}

Of the 519 individuals that participated in the EELO study, those who missed the exam date were excluded. A total of 498 subjects with a median age of 69 years were submitted to an audiological evaluation. Of these, 166 (33.33\%) were male, and 332 (66.66\%) were female.

Of the 498 subjects, 309 (62.04\%) had hypertension, and 186 (37.34\%) did not; 145 (29.11\%) had DM, and 350 (70.28\%) did not; and 118 (23.69\%) had both hypertension and DM. A total of $456(91.56 \%)$ subjects had bilateral $\mathrm{HL}$, and $42(8.43 \%)$ had unilateral HL. Using the classification of the study by Davis and Silverman, ${ }^{22} 26.50 \%$ of our sample had moderate $\mathrm{HL}$, moderate loss of $12.75 \%$ and $1.60 \%$ of gross loss and $0.70 \%$ deep loss, with $58.43 \%$ having normal hearing or decrease in the frequencies of $6,000 \mathrm{~Hz}$ and $8,000 \mathrm{~Hz}$ (-Table 1).

In order to analyze the normality of the data, the D'Agostino-Pearson test was performed. As the data were not normally distributed, we used the Mann-Whitney test for the comparison between auditory averages I $(500 \mathrm{~Hz}$, $1,000 \mathrm{~Hz}$ and $2,000 \mathrm{~Hz})$ and II $(3,000 \mathrm{~Hz}, 4,000 \mathrm{~Hz}$ and 
Table 1 Prevalence distribution according to the type and degree of hearing loss

\begin{tabular}{|l|l|l|l|l|l|}
\hline \multicolumn{4}{|l|}{ Type of hearing loss } & \multicolumn{2}{l|}{$\begin{array}{l}\text { Degree of } \\
\text { hearing loss }\end{array}$} \\
\hline & Ears & $\%$ & & Ears & $\%$ \\
\hline Sensorineural & 660 & $66.26 \%$ & Mild & 264 & $26.50 \%$ \\
\hline Mixed & 32 & $3.21 \%$ & Moderate & 127 & $12.75 \%$ \\
\hline Conductive & 0 & 0 & Severe & 16 & $1.60 \%$ \\
\hline $\begin{array}{l}\text { Normal } \\
\text { thresholds }\end{array}$ & 113 & $11.34 \%$ & Profound & 7 & $0.70 \%$ \\
\hline $\begin{array}{l}\text { Fall at } 6 \mathrm{kHz} \\
\text { and } 8 \mathrm{kHz}\end{array}$ & 191 & $19.17 \%$ & $\begin{array}{l}\text { Normal } \\
\text { thresholds or } \\
\text { fall at } 6 \mathrm{kHz} \\
\text { and } 8 \mathrm{kHz}\end{array}$ & 582 & $58.43 \%$ \\
\hline
\end{tabular}

$6,000 \mathrm{~Hz}$ ), which were obtained through audiometry and other collected data.

After verifying that there was no statistically significant difference between the right and left ears and the data of the hearing averages (means I $p=0.3294$ and $p=0.9295$ medium II) we chose to present the data from the right ear.

Comparing the auditory average I of the general data for 309 (62.04\%) subjects with hypertension and 186 (37.34\%) without hypertension, we obtained the following results: $p=0.3511 \quad(\mathrm{U}=27,568)$ for auditory average $\mathrm{I}$ and $p=0.5942(\mathrm{U}=28,188.5)$ for auditory average II.

The same comparison was performed with the general data for the 145 individuals (29.11\%) with DM, and the 350 (70.28\%) subjects without DM, and the following results were obtained: $p=0.261(\mathrm{U}=24,152)$ for auditory average I, and $p=0.2303(\mathrm{U}=24,041.5)$ for auditory average II.

Because no statistically significant values were found among the general sample, in order to eliminate possible confounding variables, we excluded from the sample subjects who consumed alcohol, smokers, former smokers and diabetics, reducing the sample to 182 subjects. In order to perform the analysis of hypertension and auditory averages I and II, we compared the auditory averages of 105 hypertensive patients ( $21.08 \%$ of the general sample, and $57.69 \%$ of the reduced sample) and 77 non-hypertensive individuals (15.46\% of the general sample and $42.30 \%$ of the reduced sample), and the following values were obtained: $p=0.9864$ $(\mathrm{U}=4,036.5)$ for auditory average $\mathrm{I}$, and $p=0.9093$ $(\mathrm{U}=4,002.5)$ for auditory average II.
For the analysis of the individuals with and without diabetes, we excluded from the sample alcohol consumers, smokers, former smokers and hypertensive individuals, reducing the sample to 89 subjects, 12 diabetic $(2.40 \%$ of the general sample and $13.48 \%$ of the reduced sample) and 77 non-diabetic (15.46\% of the overall sample and $42.30 \%$ the reduced sample), and the following values were obtained: $p=0.0609(\mathrm{U}=306)$ for auditory average $\mathrm{I}$, and $p=0.0247$ $(\mathrm{U}=275)$ for auditory average II.

By eliminating alcohol consumers, smokers and former smokers, when comparing the auditory averages of 69 (13.85\%) subjects who had both comorbidities, and 76 (15.26\%) subjects who did not have any of them, we obtained the following values: $p=0.446(\mathrm{U}=2,429.5)$ for average I, and $p=0.5022(\mathrm{U}=2,452.5)$ for average II.

For the analysis regarding age, the subjects were divided into 4 age groups: 60 to 69 years old (group1), 70 to 79 years old (group 2), 80 to 89 years old (group 3 ) and $>90$ years old (group 4). Since only 2 individuals were older than 90 years of age, they were excluded to avoid possible confounding variables due to outliers. The statistical analysis of the three age groups was performed using the Kruskal-Wallis test, followed by the Dunn post-test, and we obtained the following values: $H=69.1651$, and $p<0.0001$. For the intergroup analysis, we obtained $p$-values $<0.05$.

Of the 996 ears (498 subjects) analyzed, 660 (66.26\%) were classified as having sensorineural HL, 32 (3.21\%) as having mixed HL, 191 (19.17\%) as having normal HL at high frequencies, and 113 (11.34\%) as having auditory thresholds within normal limits.

In order to check the independent risk factors for $\mathrm{HL}$, multiple logistic regression was performed, and the following results were obtained: noise exposure, $p=0.0409$; DM, $p=0.8018$; gender, $p=0.589$; and age, $p<0.0001$ (-Table 2).

After the statistical analysis, we found that, among the analyzed variables, only gender (the prevalence was higher in males), DM and a history of exposure to occupational noise were associated with HL at high frequencies among the elderly. However, according to the multiple logistic regression, only age and exposure to occupational noise are independent risk factors for HL.

\section{Discussion}

Several studies analyze the changes in hearing, which occur with increasing age and are related to lifestyle, labor, metabolic

Table 2 Multiple logistic regression and independent risk factors for hearing loss

\begin{tabular}{|l|l|l|l|l|l|l|}
\hline Multiple logistic regression \\
\hline & Average I & \multicolumn{3}{l|}{ Average II } \\
\hline & $p$ & Odds ratio & U 95\% & $p$ & Odds ratio & U 95\% \\
\hline Intercept - Hearing loss & & & & & & \\
\hline Diabetes mellitus & 0.842 & 0.9578 & $0.63-1.46$ & 0.161 & 0.7078 & $0.44-1.15$ \\
\hline Age & $<\mathbf{0 . 0 0 0 1}$ & 1.1425 & $1.10-1.18$ & $<\mathbf{0 . 0 0 0 1}$ & 1.1596 & $1.11-1.21$ \\
\hline
\end{tabular}

U: confidence interval of the Kruskal-Wallis test. 
and circulatory disorders, infections, trauma and heredity. ${ }^{25-27}$ Hearing loss significantly increases with age. ${ }^{27,28}$

In the present study, age was a significant predictor in the gross and adjusted analyses. The results indicate that the prevalence of HL increases progressively and proportionally with age $(p<0.0001)$. Another study showed a more pronounced decrease in normal hearing at the frequencies of $2 \mathrm{kHz}, 4 \mathrm{kHz}$ and $8 \mathrm{kHz}$, which corroborates the conclusions of the present study, in which the average of $3 \mathrm{kHz} \mathrm{II}, 4 \mathrm{kHz}$ and $6 \mathrm{kHz}$ presented the largest reduction. ${ }^{29}$

Based on our findings, we conclude that there is a prevalence of sensorineural HL compared with other HLs in individuals older than 60 years of age $(66.26 \%$ with sensorineural HL, mixed HL in $3.21 \%, 19.17 \%$ with normal thresholds that declined at the frequencies of $6,000 \mathrm{~Hz}$ and $8,000 \mathrm{~Hz}$, and $11.34 \%$ with thresholds within normal limits). These results are similar to those of previous studies, ${ }^{14,19}$ which also found a prevalence of sensorineural HL, with an association between $\mathrm{HL}$ and DM or hypertension in populations of different ages, but especially among the elderly. ${ }^{8-10,30}$

Some studies point out that every cell in the body relies on an adequate supply of oxygen and nutrients to maintain its functions, depending on the structural and functional integrity of the heart and blood vessels. Hypertension can cause changes in the heart and blood vessels. The high pressure in the vascular system can result in bleeding into the inner ear, which may lead to sudden or progressive $\mathrm{HL}^{8-18}$ This result, which seems controversial when compared with the literature, is possibly due to the age of the study sample (between 60 to 97 years).

In the study by Lin et $\mathrm{al}^{25}$ there were no significant associations ( $p>0.05$ ) between HL and other cardiovascular risk factors (hypertension, diabetes), even when multiple HL frequency bands were considered. However, the authors mention limitations such as $13 \%$ of older adults who did not complete the audiometric examination. They also mentioned a low statistic power. Therefore, these prevalence rates underestimate the true prevalence of HL among the population.

As for the methodological characteristics of the present study, we did not consider variables such as alcohol consumption, smoking, diabetes (for the analysis of hypertension) and hypertension (for analysis of DM) to reduce the bias. However, the fact that the data for hypertension and diabetes were taken from the self-reported questionnaire may have affected the results. Nevertheless, the individuals who participated in this study were being cared for in BHUs in their neighborhoods, and these units periodically check the diseases of their patients, increasing data reliability. The present study found that sensorineural is the main type of $\mathrm{HL}$ among individuals over the age of 60 , and this proportion increased gradually with age.

The risk factors, DM and age, predispose the individuals to HL, especially when associated with presbycusis. However, only age and exposure to occupational noise are independent factors for $\mathrm{HL}$, and the elderly have $\sim 1.14$ more chances of having hearing acuity compared with younger adults. We hope that the data obtained in this study may contribute to foster preventive health strategies.

Information about the greater probability of HL due to DM encourage the periodic monitoring of the auditory health of the elderly, as well as strategies for the prevention and monitoring of metabolic problems such as diabetes. Prophylactic measures to minimize the effects of aging can also help control HL and decrease the psychosocial impact on these individuals.

\section{Conclusion}

There is a high prevalence of sensorineural HL among individuals over 60 years of age (66.26\%), mostly bilateral (91.56\%) and mild (26.50\%) HL, and a progressive decrease in hearing thresholds with age.

We found statistically significant associations between $\mathrm{HL}$ at high frequencies and the variables age, DM, male gender and exposure to occupational noise. However, only exposure to occupational noise and age were considered independents risk factors for hearing loss.

\section{References}

1 World Health Organization (WHO). World Health Report 2010. Geneva: WHO; 2010

2 Brazilian Institute of Geography and Statistics. Summary of social indicators 2010. Rio de Janeiro: IBGE; 2011

3 Lima MG, Barros MB, César CL, Goldbaum M, Carandina L, Ciconelli RM. Impact of chronic disease on quality of life among the elderly in the state of São Paulo, Brazil: a population-based study. Rev Panam Salud Publica 2009;25(04):314-321

4 Roth TN, Hanebuth D, Probst R. Prevalence of age-related hearing loss in Europe: a review. Eur Arch Otorhinolaryngol 2011;268 (08):1101-1107

5 Paiva KM, Cesar CL, Alves MC, Barros MB, Carandina L, Goldbaum M. [Aging and self-reported hearing loss: a population-based study]. Cad Saude Publica 2011;27(07):1292-1300

6 Agrawal Y, Platz EA, Niparko JK. Risk factors for hearing loss in US adults: data from the National Health and Nutrition Examination Survey, 1999 to 2002. Otol Neurotol 2009;30(02):139-145

7 Mattos LC, Veras RP. The prevalence of hearing loss in an elderly population in Rio de Janeiro: a cross-sectional study. Rev Bras Otorrinolaringol (Engl Ed) 2007;73(05):654-659

8 de Moraes Marchiori LL, de Almeida Rego Filho E, Matsuo T. Hypertension as a factor associated with hearing loss. Rev Bras Otorrinolaringol (Engl Ed) 2006;72(04):533-540

9 Marchiori LLM, Rego Filho EA. Queixa de vertigem e hipertensão arterial. Rev CEFAC 2007;9(01):116-121

10 Melo JJ, Meneses CL, Marchiori LL. Prevalence of tinnitus in elderly individuals with and without history of occupational noise exposure. Int Arch Otorhinolaryngol 2012;16(02):222-254

11 Asakura K, Nishiwaki Y, Milojevic A, et al. Lifestyle factors and visible skin aging in a population of Japanese elders. J Epidemiol 2009;19(05):251-259

12 Marchiori LLM. Zumbido e hipertensão arterial no processo de envelhecimento. Rev Bras Hipertens. 2009;16(01):5-8

13 Mondelli MFCG, Lopes AC. Relação entre a hipertensão arterial e a deficiência auditiva. Int Arch Otorrinolaringol. 2009;13(01):63-68

14 Meneses C, Mário MP, Marchori LLM, Melo JJ, Freitas ERFS. Prevalência de perda auditiva e fatores associados na população idosa de Londrina, Paraná: estudo preliminar. Rev CEFAC 2010; 12:384-392

15 Lethbridge-Cejku M, Schiller JS, Bernadel L. Summary health statistics for U.S. adults: National Health Interview Survey, 2002. Vital Health Stat 10 2004;222(222):1-151

16 Cruickshanks KJ, Wiley TL, Tweed TS, et al; The Epidemiology of Hearing Loss Study. Prevalence of hearing loss in older adults in Beaver Dam, Wisconsin. Am J Epidemiol 1998; 148(09):879-886 
17 Krishnamurti S. Sensorineural hearing loss associated with occupational noise exposure: effects of age-corrections. Int J Environ Res Public Health 2009;6(03):889-899

18 Baraldi GS, Almeida LC, Borges ACC. Perda auditiva e hipertensão: achados em grupo de idosos. Rev Bras Otorrinolaringol 2004;70 (05):640-644

19 Gibrin PCD, Melo JJ, Marchiori LLM. Prevalence of tinnitus complaints and probable association with hearing loss, diabetes mellitus and hypertension in elderly. CoDAS 2013;25(02): 176-180

20 Spidurso WW. Dimensões físicas do envelhecimento. Barueri: Manole; 2005

21 Miller MH. A integração dos achados audiológicos. In: Katz J (Org). Tratado de audiologia clínica. São Paulo: Manole; 1999;13:268-270

22 Davis H, Silverman SR. Hearing and deafness. New York: Holt, Rinehart and Winston; 1970

23 National Committee on Noise and Hearing Conservation Recommendations for the assessment of damage caused by Noise Induced Hearing Loss, Carta aos editores. Acta AWHO. 1996; $16: 45$
24 Amorim RB, Lopes AC, Santos KTP, Melo ADP, Lauris JRP. Auditory Alterations for Occupational Exposition in Musicians. Arq Int Otorrinolaringol 2008;12(03):377-383

25 Lin FR, Thorpe R, Gordon-Salant S, Ferrucci L. Hearing loss prevalence and risk factors among older adults in the United States. J Gerontol A Biol Sci Med Sci 2011;66(05):582-590

26 Hickson L, Wood J, Chaparro A, Lacherez P, Marszalek R. Hearing impairment affects older people's ability to drive in the presence of distracters. J Am Geriatr Soc 2010;58(06):1097-1103

27 Huang Q, Tang J. Age-related hearing loss or presbycusis. Eur Arch Otorhinolaryngol 2010;267(08):1179-1191

28 Quaranta N, Coppola F, Casulli M, et al. Epidemiology of age related hearing loss: A review. Hear Balance Commun 2015;13 (02):1-5; Early Online

29 Çayönü M, Çapraz M, Acar A, Altundağ A, Salihoğlu M. Hearing Loss Related with Type 2 Diabetes in an Elderly Population. Int Adv Otol. 2014;10(01):72-75

30 Ferreira LMBM, Ramos Júnior AN, Mendes EP. Caracterização do zumbido em idosos e de possíveis transtornos relacionados. Rev Bras Otorrinolaringol 2009;75(02):245-248 